\title{
An assessment of the community based distribution programs in Ghana
}

\author{
Jane Chege \\ Population Council \\ Diouratie Sanogo \\ Population Council \\ Ian Askew \\ Population Council \\ Angela Bannerman \\ Steve Grey
}

See next page for additional authors

Follow this and additional works at: https://knowledgecommons.popcouncil.org/departments_sbsr-rh

Part of the Demography, Population, and Ecology Commons, International Public Health Commons, Public Health Education and Promotion Commons, and the Women's Health Commons How does access to this work benefit you? Let us know!

\section{Recommended Citation}

Chege, Jane, Diouratie Sanogo, Ian Askew, Angela Bannerman, Steve Grey, Evam Kofi Glover, Francis Yankey, and Joana Nerquaye-Tetteh. 2000. "An assessment of the community based distribution programs in Ghana," FRONTIERS Final Report. Washington, DC: Population Council. 


\section{Authors}

Jane Chege, Diouratie Sanogo, lan Askew, Angela Bannerman, Steve Grey, Evam Kofi Glover, Francis Yankey, and Joana Nerquaye-Tetteh 


\title{
An Assessment of the Community Based Distribution Programs in Ghana
}

\author{
Population Council \\ Jane Chege \\ Diouratié Sanogo \\ Ian Askew \\ Planned Parenthood Association of Ghana \\ Angela Bannerman \\ Steve Grey \\ Evam Kofi Glover \\ Francis Yankey \\ Joana Nerquaye-Tetteh
}

November 2000

An Assessment of the Community Based Distribution Programs in Ghana. This study was funded by the UNITED STATES AGENCY FOR INTERNATIONAL DEVELOPMENT (USAID) under the terms of Cooperative Agreement number HRN-A-00-98-00012-00 and Subproject number A199.64A. The opinions expressed herein are those of the authors and do not necessarily reflect the view of USAID. 



\section{SUMMARY}

Several organizations, including the Ministry of Health (MOH) and about 20 Non-Governmental Organisations (NGOs), currently provide sexual and reproductive health services through Community Based Distribution (CBD) programs. Planned Parenthood Association of Ghana (PPAG), (IPPF-affiliate), runs the largest CBD program, established 25 years ago. However, there has been little systematic documentation of the different NGO programs in the country, the range of services they offer, their geographical coverage, or the effectiveness of the strategies they employ. As a result, sometimes there has been duplication of programs and difficulties in making the best use of existing resources.

This study was carried out for two reasons: to describe the major NGO CBD programs in the country, and to assess in some detail the functioning, quality of care and performance of the PPAG program. The results are to be used to strengthen future development of the NGO programs, to inform the $\mathrm{MOH}$ on the role of these $\mathrm{CBD}$ models within the overall Primary Health care program, and to guide partner organizations, notably USAID, in working with PPAG's and other CBD programs.

Thirteen NGOs were covered in the study. Information was gathered through interviews and a documentary review at the organizations' headquarters. More detailed information was collected from PPAG including: visits to 16 districts in eight regions, where $301 \mathrm{CBD}$ agents, 27 supervisors and 20 staff at referral clinics were interviewed. In addition, each of $51 \mathrm{CBD}$ agents was observed interacting with six clients, and 15 focus group discussions were held with community representatives, former agents and clients of CBD agents. PPAG uses three CBD models - the traditional model; the youth model; and the sexual health model - and data were collected so that all three models could be assessed.

The study showed that national coverage by the NGO programs is extensive - virtually all the 110 districts in the 10 regions have at least one program. However, coverage within districts is sparse, as each program covers only a few communities. Some districts have a disproportionately higher concentration of programs and agents than others do with higher populations.

The programs have differences in the range of services provided, and the status and remuneration of agents and supervisors. All programs provide family planning information and education, distribute condoms and pills and refer clients for clinical family planning methods. A number of programs also provide information and education on STIs and HIV/AIDS, and the Ghana Registered Midwives Association (GRMA) provides other Maternal Child Health services, while the Christian Council of Ghana (CCG) provides home-based care for people living with HIV/AIDS.

All the programs use trained supervisors, who are either part- or full-time employees. Only GRMA has full-time CBD agents; all others use part-time volunteers who receive a small monthly allowance or a commission on sales of contraceptives. Most programs provide a nonmonetary incentive such as bicycles, boots, raincoats, T-shirts or an initial supply first aid drug kits.

Although all programs have trained their agents to maintain activity records, record keeping and reporting was found to be universally poor. Moreover, the quality of reports was insufficient to 
inform program management and donors about the programs' performance, and made impossible a comparison and evaluation of the different programs.

A good proportion of PPAG agents (60\%) were satisfied with the frequency of supervision. Fulltime supervisors made more frequent supervisory contacts with agents than part-time supervisors. All PPAG agents have received basic training in family planning and 92 percent have been trained in providing services and information to young people. Generally, the agents' and supervisors' knowledge of family planning was adequate, although knowledge of the pill's side effects was poor. Knowledge of STIs, including HIV/AIDS, was limited. Not many agents were observed to use the pill checklist to assess new client's suitability for the method, but they did provide the necessary information on method use.

A particular strength of the PPAG program was that most clients were observed to receive information on STIs, and most were given a dual protection message about condoms. However, the agents did not always provide other reproductive health-related information to clients; for instance, only in 22 percent of cases were mothers with young children given information on immunization and growth monitoring.

Although PPAG has a youth-oriented CBD program, the agents and supervisors in all three models had a negatively biased attitude toward giving information and services to youth, especially those with no children. However, female agents had a more favorable attitude than male agents.

The results have been communicated to the NGOs whose programs were included in the study. PPAG has already identified a number of steps that it will take to address some of the issues raised. These include: a revision of the training manual, introduction of a community diagnosis and mapping exercise for each agent; improved record keeping and reporting procedures; establishing stronger links with referral clinics; and enhancing the availability of educational materials for use when counseling clients. In addition, USAID will be using the results to guide future programming of its support to the PPAG program. 


\section{CONTENTS}

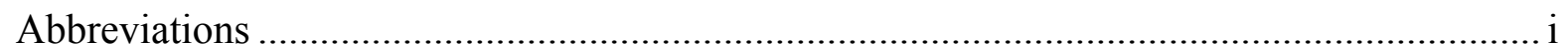

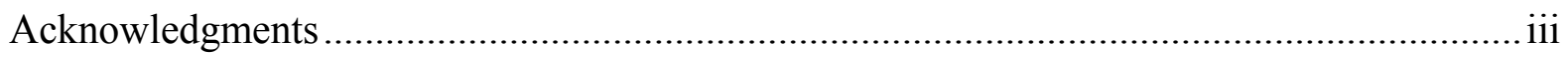

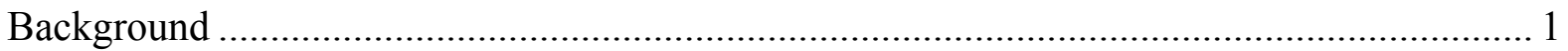

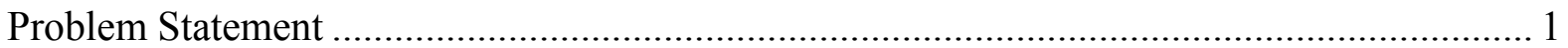

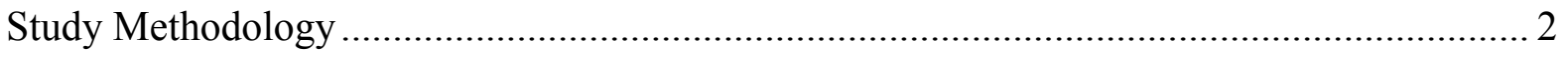

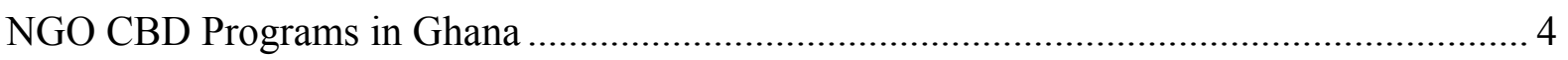

Programs' Coverage ..................................................................................... 4

Agent Characteristics, Recruitment And Training..................................................... 4

Services Provided By CBD Agents .................................................................... 6

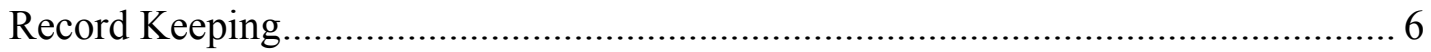

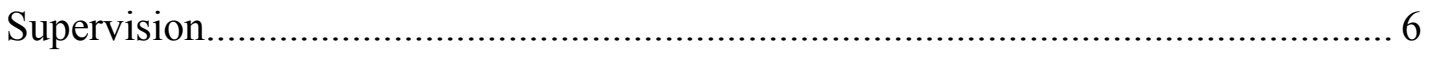

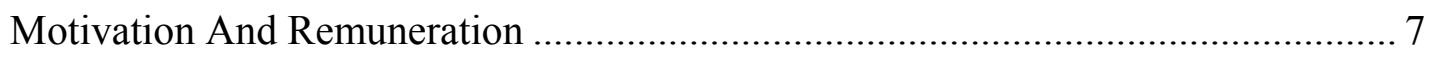

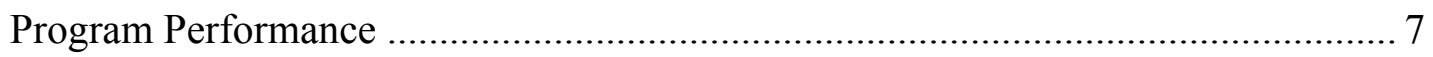

PPAG's CBD Program........................................................................................... 8

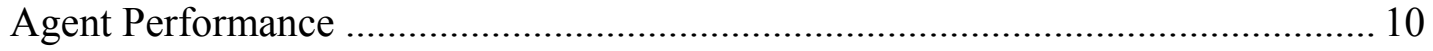

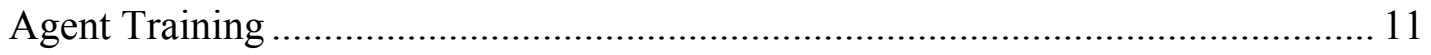

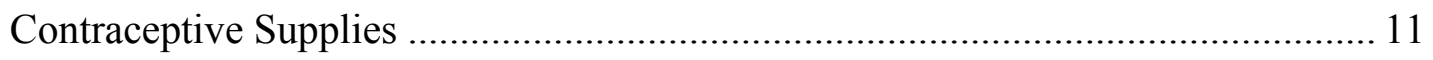

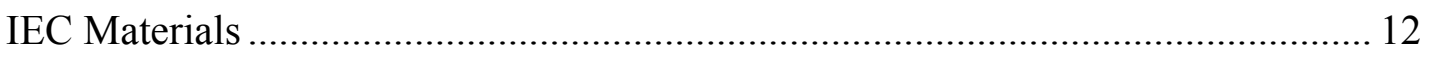

Record Keeping And Reporting..................................................................... 12

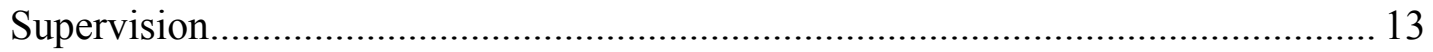

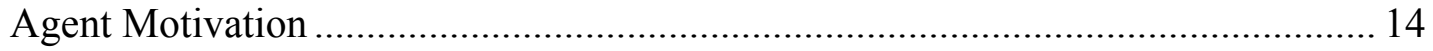

Quality Of Care Provided By PPAG Agents ........................................................... 14

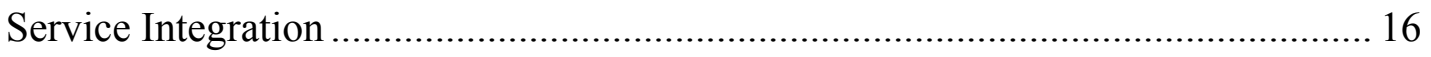

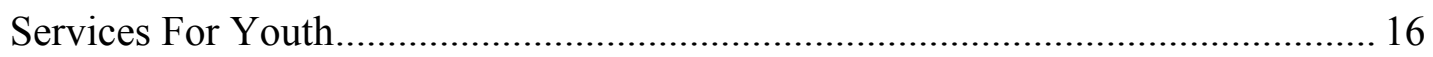

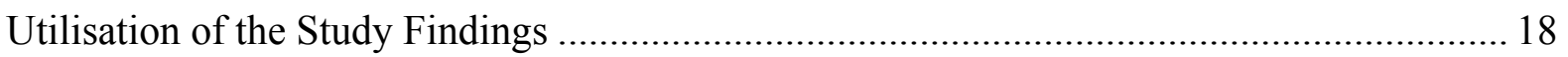

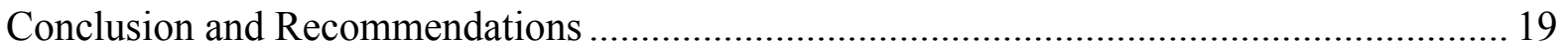

All NGO CBD Programs ……………………………........................................ 19

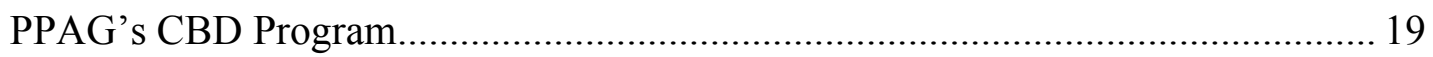

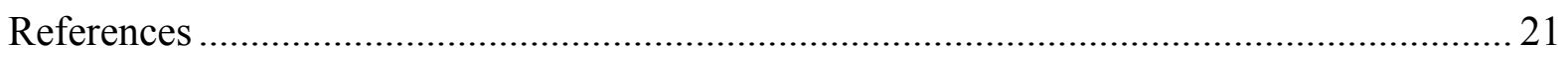

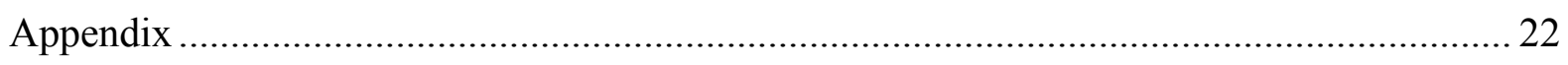




\section{TABLES AND FIGURES}

Table 1: Organizations Included in the Survey (1999) .................................................. 4

Table 2: CBD Programs' Concentration, Approximate

Number Of Agents And Total Population Covered Per Region ........................................... 6

Table 3: Average number of Family Planning Outputs per CBD Agent per Year ........... 11

Table 4: Proportion of Agents Who Had IEC Materials By CBD Model......................... 12

Table 5: Proportion of Agents Who Had MIS Materials By CBD Model........................ 13

Figure 1: Average Number Of New FP Clients Per CBD Agent In 1999 ......................... 9

Figure 2: Number Of Supervisory Visits Received Per Agent

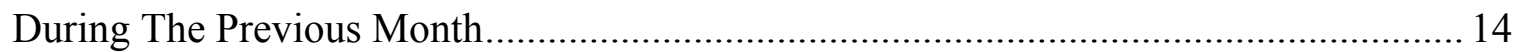




\section{AbBreviations}

ADRA

AIDS

AMA

AR

BA

CBD

CCG

CENCOSAD

CR

CYP

DfID

ER

FGDs

FP

GDHS

GR

GRMA

GUNSA

HIV

IAE

ICPD

IGAs

INTRAH

IPPF
Adventist Development and Relief Agency

Acquired Immune Deficiency Syndrome

Accra Metropolitan Assembly

Ashanti Region

Brong Ahafo Region

Community-Based Distribution

Christian Council of Ghana

Centre for Community Studies, Action and Development

Central Region

Couple Years Protection

Department for International Development

Eastern Region

Focus Group Discussions

Family Planning

Ghana Demographic \& Health Survey

Greater Accra

Ghana Registered Midwives Association

Ghana United Nations Students Association

Human Immuno-Deficiency Virus

Institute of Adult Education

International Conference on Population and Development

Income Generating Agencies

International Training in Health

International Planned Parenthood Federation 


\begin{tabular}{|c|c|}
\hline IUCD & Intra-Uterine Contraceptive Device \\
\hline JICA & Japan International Co-operation Agency \\
\hline JOICFP & Japanese Organization for International Cooperation in Family Planning \\
\hline $\mathrm{MCH}$ & Maternal and Child Health \\
\hline MFCS & Muslim Family Counselling Services \\
\hline $\mathrm{MOH}$ & Ministry of Health \\
\hline NGOs & Non-Governmental Organizations \\
\hline NR & Northern Region \\
\hline NHRC & Navrongo Health Research Centre \\
\hline PPAG & Planned Parenthood Association of Ghana \\
\hline RH & Reproductive Health \\
\hline RTIs & Reproductive Tract Infections \\
\hline $\mathrm{SRH}$ & Sexual and Reproductive Health \\
\hline $\mathrm{SCF}$ & Save the Children Fund \\
\hline STIs & Sexually Transmitted Infections \\
\hline TFR & Total Fertility Rate \\
\hline UE & Upper East Region \\
\hline UNFPA & United Nations Population Fund \\
\hline USAID & United States Agency for International Development \\
\hline UW & Upper West Region \\
\hline WR & Western Region \\
\hline YMCA & Young Men's Christian Association \\
\hline YWCA & Young Women's Christian Association \\
\hline YDF & Youth Development Foundation \\
\hline $31^{\text {st }} \mathrm{DWM}$ & 31st December Women's Movement \\
\hline
\end{tabular}




\section{ACKNOWLEDGMENTS}

This study is an outcome of a collaborative effort between PPAG, Population Council, and USAID/Ghana. We would like to express our sincere appreciation to the managers and staff of these organizations for their valuable support to the study. In particular we would like to thank Laura Slobey and Lawrence Aduomum-Darko of USAID, for providing technical support, and sharing their experiences and perceptions of Community Based Distribution (CBD) in Ghana. We are also greatly indebted to the programs managers of the Young Women Christian Association, Young Men Christian Association, Ghana United Nations Students Association, MAYDAY Rural Project, CARE Ghana, PLAN International Ghana, Ghana Registered Midwives Association, Muslim Family Counselling Services, Christian Council of Ghana, Adventist Development Relief Agency, Amasachina and Institute of Adult Education for sharing information relating to their programs.

We appreciate the dedicated participation in the fieldwork of Lulu Ahenkan-Yeboah, Esther Nagawa, Joyce Lartey, Maxwell Gyening, George Anarwat and Phyllis Sackey. Elizabeth Hammah, Selina Esantsi, Wisdom Mortoti, Paapa Agyepong participated in both fieldwork and data processing while Emelia Takyi was involved in data processing. We thank Mr. Alex Amakwah- Poku (MIS Officer, PPAG) for his participation in the development of data instruments and acknowledge the CBD Agents and Supervisors, Peer educators and Referral Point Staff who participated in the study through interviews and focus group discussions. We are indebted to these who contributed to the successful completion of the study.

Finally, we express our gratitude to the USAID without whose funding and support this study would not have been possible. 


\section{BACKGROUND}

Ghana, with a landmass of 92,100 square miles and a population of nearly 20 million inhabitants, is one of the most populous countries in West Africa, second to only Nigeria. Despite recent evidence from both the 1993 and 1998 Ghana Demographic and Health Surveys (GDHS) suggesting a declining trend in mortality and fertility, levels remain relatively high. Infant mortality dropped from 77 deaths per 1000 in 1993 to 66 in 1998, and child mortality from 155 to 119 deaths for 1000 births. Total fertility rate (TFR) also dropped from 6.4 children in 1993 to 4.6 in 1998 for women in the 15-49 age group, although with wide variations by place of residence, region and education. Actual fertility contrasts with fertility preferences - the 1998 GDHS indicates that the average ideal family size for currently married women is estimated to be four children.

Since 1970, Ghana has received external funding for its family planning activities. The major funding agencies are USAID, UNFPA, DfID, IPPF, and recently the World Bank. Even though family planning services have been provided for several years, and the GDHS shows that knowledge of contraception is almost universal, only 13 percent of married women were using a modern method in 1998 (although prevalence varies widely by location, region and education level). In addition, 23 percent of demand for family planning is currently unmet.

Various groups provide Sexual and Reproductive Health (SRH) services in Ghana, including governmental and quasi-government organizations, private organizations, and non-governmental organizations (NGOs). Most family planning services are provided in fixed clinics. There is, however, an increasingly successful social marketing program and several groups are implementing community-based models of service delivery.

For example, the $\mathrm{MOH}$, with support from USAID and the Rockefeller Foundation and through technical assistance from the Population Council, is currently expanding a community-based service delivery model originally developed by the Navrongo Health Research Centre at the district level throughout the country. Over 20 NGOs have been implementing CBD projects of varying scale (JOICFP/PPAG 1998), with Planned Parenthood Association of Ghana (PPAG) as the oldest and most developed. PPAG is the IPPF affiliate in Ghana. The organization introduced the first community-based family planning information and services program in Ghana 25 years ago.

\section{Problem Statement}

The Government of Ghana promotes the CBD delivery approach as an important strategy that is crucial for meeting the SRH concerns of the people, especially in the rural and peri-urban populations. To date, however, there is hardly any documentation of the different programs, their geographic coverage, the strategies they use, or their effectiveness. The lack of this type of information has sometimes led to duplication of efforts, as well as to problems with maximizing the use of the limited resources available. 
Experience in a variety of settings has shown that community-based distribution of contraceptives and other SRH services can improve their accessibility, quality, acceptability, and impact. A review of CBD programs in Africa (Phillips et al, 1999) indicates that they sometimes fail because of their inability to adapt to the local environment or because of their failure to build commitment. Lessons learned from several operations research studies on CBD in Africa (Africa OR/TA Project II, 1999) indicate that the following are crucial elements in the successful implementation of CBD programs: quality of care provided by the agents; agents' remuneration and job satisfaction; supervision and management structures; and the type of information and services agents provide.

Apart from some small-scale studies aimed at improving specific program elements (e.g. INTRAH/PRIME, 1996; JOICFP/PPAG, 1998; PPAG Annual Reports), the experience of PPAG and other NGOs in implementing CBD programs has not been systematically documented or assessed. If PPAG and other NGOs are to successfully expand their CBD programs, as is the intention of the NGOs and the $\mathrm{MOH}$, as well as the principal donors (USAID, UNFPA), there is need to examine the current programs in light of these elements.

Because it is the largest and oldest CBD program in the country, an assessment of PPAG's program will provide guidance for many of the smaller NGO programs. In addition, the $\mathrm{MOH}$ sees the development of community-based service delivery models as essential for the future of health care in Ghana, and has put a lot of emphasis on the Primary Health Care program. It is therefore committed to learning about existing alternatives in both the public and private sectors, which use community mobilization as a hallmark for sustainability of health programs.

\section{STUDY METHODOLOGY}

The ultimate objective of this study is to provide information to guide the design, management and implementation of community-based reproductive health services. Specifically, the study sought to:

- Determine and map the geographic coverage of all CBD programs in Ghana;

- Describe the structure and functioning of PPAG's and other CBD programs;

- Measure the performance of PPAG CBD agents;

- Estimate the population covered by PPAG agents within their catchment communities;

- Assess the effectiveness of the CBD program's referral systems;

- Ascertain the perceptions of staff and managers concerning the functioning of the CBD programs;

- Determine whether there are client needs that are not being met, and whether there are different groups of potential clients who are not being reached by the programs.

The assessment included 13 CBD programs implemented by NGOs, but with a more detailed focus on PPAG's programs (see Table 1). Information on how the programs function was collected from the NGOs head offices. 
Detailed data on PPAG's program were collected through interviews with CBD agents, CBD supervisors, and referral clinic staff, through focus group discussions with community members in the programs' catchment areas, and through observations of agent-client interactions. It was impossible to obtain data on program costs, which would have been used to carry out a cost analysis.

Table 1: Organizations included in the survey (1999)

\begin{tabular}{|c|c|c|c|c|c|c|c|}
\hline Agency & $\begin{array}{c}\text { Type of } \\
\text { NGO }\end{array}$ & $\begin{array}{c}\text { Year } \\
\text { started }\end{array}$ & $\begin{array}{l}\text { Number } \\
\text { of agents }\end{array}$ & $\begin{array}{c}\text { Number of } \\
\text { supervisors }\end{array}$ & $\begin{array}{c}\text { Status of } \\
\text { supervisors }\end{array}$ & $\begin{array}{r}\text { Cove } \\
\text { Regions }\end{array}$ & $\begin{array}{l}\text { rage } \\
\text { Districts }\end{array}$ \\
\hline ADRA & $\begin{array}{l}\text { International } \\
\text { religious }\end{array}$ & 1994 & 100 & 10 & Part-time & 3 & 3 \\
\hline Amasachina & $\begin{array}{l}\text { National } \\
\text { Secular }\end{array}$ & 1994 & 87 & 15 & $\begin{array}{l}\text { Full- and part- } \\
\text { time }\end{array}$ & 1 & 13 \\
\hline CARE & $\begin{array}{l}\text { International } \\
\text { secular }\end{array}$ & 1999 & 150 & 6 & Full-time & 1 & 1 \\
\hline$\overline{C C G}$ & $\begin{array}{l}\text { National } \\
\text { religious }\end{array}$ & 1994 & 60 & 3 & Full-time & 2 & 4 \\
\hline GRMA & $\begin{array}{l}\text { National } \\
\text { secular }\end{array}$ & 1997 & 264 & 268 & Full-time & 10 & 110 \\
\hline GUNSA & $\begin{array}{l}\text { National } \\
\text { secular }\end{array}$ & 1999 & 45 & 6 & Part-time & 1 & 3 \\
\hline$\overline{\mathrm{IAE}}$ & $\begin{array}{l}\text { Public } \\
\text { secular }\end{array}$ & 1997 & 171 & 23 & Part-time & 3 & 14 \\
\hline MAYDAY & $\begin{array}{l}\text { National } \\
\text { secular }\end{array}$ & 1987 & 182 & 13 & Part-time & 2 & 2 \\
\hline MFCS & $\begin{array}{l}\text { National } \\
\text { religious }\end{array}$ & 1994 & 27 & 6 & Part-time & 4 & 4 \\
\hline PLAN & $\begin{array}{l}\text { International } \\
\text { secular }\end{array}$ & 1996 & 110 & 36 & $\begin{array}{l}\text { Full- and part- } \\
\text { time }\end{array}$ & 3 & 3 \\
\hline PPAG & $\begin{array}{l}\text { National } \\
\text { secular }\end{array}$ & 1974 & $853^{1}$ & 102 & $\begin{array}{l}\text { Full- and part- } \\
\text { time }\end{array}$ & 8 & $53^{2}$ \\
\hline YMCA & $\begin{array}{l}\text { International } \\
\text { religious }\end{array}$ & 1997 & 60 & 3 & Full-time & 1 & 1 \\
\hline$\overline{Y W C A}$ & $\begin{array}{l}\text { International } \\
\text { religious }\end{array}$ & 1993 & 20 & 3 & Part-time & 6 & 7 \\
\hline
\end{tabular}

${ }^{1}$ This number is exclusive of peer promoters

${ }^{2}$ This excludes the 4 districts that have peer promoters only 


\section{NGO CBD Programs in GHANA}

\section{Programs' Coverage}

Although CBD programs are found in all 10 regions and 110 districts in Ghana, coverage within districts is sparse (see Table 2), usually being restricted to a few communities only. This low level of access to community-based programs is confirmed by the 1998 GDHS, which reported that only two percent of current modern method users received their contraceptive method from a field worker. Greater Accra has the highest number of CBD programs, followed by Eastern Region. In 80 districts there are more than one CBD program operating, with Accra Metropolitan Assembly (AMA) and Kumasi districts having the most programs. PPAG and the Ghana Registered Midwives Association (GRMA) have the widest coverage and the most agents (see Appendix).

CBD agents operate in both urban and rural areas, although some programs operate only in urban or rural areas, and some in both. Some, such as the Young Women's Christian Association (YWCA), the Muslim Family Counselling Services (MFCS), and the GRMA, have a few agents covering small catchment areas and are spread across several districts in different regions. Others, such as the Institute of Adult Education (IAE), the Ghana United Nations Students' Association (GUNSA), and the Adventist Development and Relief Agency (ADRA) have more agents who cover fewer districts and regions.

\section{Agent Characteristics, Recruitment And Training}

Literacy, age, good interpersonal skills, and residence in the community are some of the criteria used in selecting CBD agents by the majority of these programs (except where illiteracy is high). Apart from the YMCA program, which has an age limit of between 14 and 25 years, most programs prefer agents who are between 18 and 45 years old. PLAN International and PPAG also require the agents to have a regular source of income.

Some programs (e.g. MAYDAY, PPAG, and CARE) involve community representatives in the recruitment process, while others (e.g. YWCA, Christian Council of Ghana (CCG), IAE, and MFCS) use local religious groups and/or District Assemblies.

Apart from the IAE and GRMA, most programs have adopted the PPAG CBD curriculum to train both their agents and supervisors. This 14-day curriculum covers family planning, human anatomy and physiology, STDs, HIV/AIDS, infertility/sub-fertility, commodity management, community diagnosis, record keeping and reporting, and gender, population and development. IAE has developed a similar training curriculum, which GRMA has adopted and modified to include safe motherhood. 
Table 2: CBD Programs' Concentration, Approximate Number Of Agents And Total Population Covered Per Region

\begin{tabular}{|c|c|c|c|c|}
\hline $\begin{array}{l}\text { Region } \\
\text { and } \\
\text { Number of } \\
\text { Districts }\end{array}$ & $\begin{array}{l}\text { Programs, Districts covered, and } \\
\text { number of agents per Program }\end{array}$ & $\begin{array}{l}\text { Approximate } \\
\text { total no. of } \\
\text { agents }\end{array}$ & $\begin{array}{l}\text { Total } \\
\text { Population } \\
\text { in Region }\end{array}$ & $\begin{array}{l}\text { Approx. } \\
\text { Population } \\
\text { per Agent }\end{array}$ \\
\hline $\begin{array}{l}\text { Greater } \\
\text { Accra (5) }\end{array}$ & $\begin{array}{l}\text { PPAG (5:137), MAYDAY (1:120), } \\
\text { PLAN (1: 28) GUNSA (3:45), } \\
\text { YWCA (1:3), GRMA (5:10), CCG } \\
(1: 15), \text { MFCS }(1: 8), 31 \text { st DWM } \\
\left(5: \text { NA }^{4}\right)\end{array}$ & $366+$ & $2,909,683$ & 7,600 \\
\hline $\begin{array}{l}\text { Eastern } \\
(15)\end{array}$ & $\begin{array}{l}\text { PPAG (12:157), MAYDAY (1:62), } \\
\text { PLAN (1:28), ADRA (1:30), GRMA } \\
\text { (14:28), YWCA (1:3), MFCS (1:2), } \\
\text { 31st DWM (15: NA) }\end{array}$ & $368+$ & $2,108,852$ & 5,200 \\
\hline $\begin{array}{l}\text { Ashanti } \\
\text { (18) }\end{array}$ & $\begin{array}{l}\text { PPAG (15: 190), GRMA (18:34), } \\
\text { ADRA (1:40), CCG (1:15), MFCS } \\
\text { (1:15), YWCA (1:3), 31st DWM } \\
\text { (18:NA), YDF (4:68) }\end{array}$ & $365+$ & $3,049,912$ & 7,300 \\
\hline Volta (12) & $\begin{array}{l}\text { PPAG (2:110), GRMA (12:24), } \\
\text { YWCA (1:3), CCG (2:30), IAE } \\
(12: 99) 31 \text { st DWM (12: NA) }\end{array}$ & $266+$ & $1,612,299$ & 5,300 \\
\hline $\begin{array}{c}\text { Brong } \\
\text { Ahafo (13) }\end{array}$ & $\begin{array}{l}\text { PPAG (5:92), ADRA (1:30) YWCA } \\
\text { (1:3), GRMA (13:26), MFCS (1:2), } \\
\text { 31st DWM (13:NA) }\end{array}$ & $153+$ & $1,824,822$ & 9,500 \\
\hline $\begin{array}{l}\text { Northern } \\
\text { (13) }\end{array}$ & $\begin{array}{l}\text { PPAG (7: 105), GRMA (13:26), } \\
\text { 31st DWM (13:NA), Amasachina } \\
\text { (13:105), Action Aid (7:NA) }\end{array}$ & $236+$ & $1,854,994$ & 6,200 \\
\hline $\begin{array}{l}\text { Central } \\
(12)\end{array}$ & $\begin{array}{l}\text { PPAG (7:132), PLAN (2:56), GRMA } \\
(11: 22), \text { YWCA (1:3) }\end{array}$ & 213 & $1,580,047$ & 7,400 \\
\hline $\begin{array}{l}\text { Western } \\
\quad(11)\end{array}$ & $\begin{array}{l}\text { PPAG (5:136), GRMA (11:22), } \\
\text { CARE (1:150) }\end{array}$ & 208 & $1,842,878$ & 8,800 \\
\hline $\begin{array}{l}\text { Upper East } \\
\text { (6) }\end{array}$ & $\begin{array}{l}\text { GRMA (6:12), IAE (6:54), MOH } \\
\text { (1:NA), Action Aid (1:NA) }\end{array}$ & $66+$ & 971,251 & 10,600 \\
\hline $\begin{array}{c}\text { Upper } \\
\text { West (5) }\end{array}$ & $\begin{array}{l}\text { GRMA (5:10), IAE (4:36) Action Aid } \\
(2: N A)\end{array}$ & 46 & 573,860 & 10,000 \\
\hline
\end{tabular}

\footnotetext{
${ }^{3}$ Source: Ghana 2000 National Census Preliminary Data

${ }^{4}$ NA (Not Available): Data on number of agents for $31^{\text {st }}$ DWM and Action Aid was not provided
} 


\section{Services Provided By CBD Agents}

All CBD programs provide family planning information and education. They also distribute condoms, oral contraceptive pills and refer clients for clinical methods, as well as other basic health services. Most programs train their agents to provide information and education on STDs and HIV/AIDS; CCG's agents also provide home-based care to people living with AIDS. PPAG agents treat minor ailments and are expected to organize environmental health and sanitation activities within their communities. GRMA agents also provide pre-natal, post-natal and delivery services to clients at the community level. Some programs (e.g. GUNSA, YMCA and PPAG) have recruited younger agents as youth peer educators.

All programs use individual home visits by their agents to provide information and services. In addition, the YWCA, GUNSA, and PPAG programs use community rallies, drama, video shows, and group discussions to provide information to their communities. The IAE program also produces a newspaper and other IEC materials in which community members are involved.

\section{Record Keeping}

All programs expect their agents to keep monthly records of their activities, including numbers of new, re-supply, and referral clients, as well as the number of contraceptive and other health care commodities dispensed. The records kept vary from program to program and is determined by the range of services the agents provide. ADRA has trained its illiterate agents to use pictorial methods for record keeping. PPAG agents also keep records of all contacts made for educational or information giving purposes (i.e. with individuals, home visits, rallies, and group meetings, drama and video contacts).

For all programs, supervisors use the agents' records to compile monthly, quarterly and annual performance reports for their area of coverage. These reports are supposed to be submitted to headquarters, usually via district or regional channels. This survey found, however, that record keeping in all programs is extremely poor, and whatever records are collected are often not reported through the program structure. There is no feedback to supervisors and agents, and the quality of the reports at headquarters level is not sufficient to inform senior management and donors about program performance.

There exists no policy guidelines or mechanism to ensure that NGO programs submit their CBD records to the National Population Council. Even at the district, regional and national levels, NGOs are not required to forward their output to the respective $\mathrm{MOH}$ officials.

\section{Supervision}

Programs may have full-time or part-time supervisors, and PPAG, PLAN International and Amasachina have both. Some programs with full-time supervisors have high ratios of agents to supervisors, such as the YMCA (20:1) and CARE (25:1). Some programs, such as CCG, MAYDAY and ADRA, which rely on part-time supervisors, also have a high agent to supervisor ratio (20:1, 14:1, 10:1 respectively). Others, such as MFCS, GUNSA, and IAE, have a ratio of 
between five and eight agents per supervisor. Since increasing the number of part-time supervisors, the agent/supervisor ratio for the PPAG program has dropped from 18 to one in 1998 to 8 to one in 1999. GRMA, with the largest number of supervisors, has a 1:1 agent to supervisor ratio.

For most programs, supervisors are required to have monthly contact with individual or groups of CBD agents; GUNSA and CCG require weekly supervisory contacts. Only the PPAG, YWCA and CCG program managers mentioned that their supervisors and agents keep monthly work plans that assist in supervision of both the agents and their immediate supervisors.

\section{Motivation And Remuneration}

Apart from the GRMA, whose agents are full-time employees of the private midwives, all other programs have agents who are part-time volunteers. They all receive a small monthly monetary allowance ranging between 5,000-30,000 $\mathrm{Cedis}^{5}$, and/or keep a commission on sale of contraceptives. For example, the YWCA, ADRA and Amasachina give their agents a monthly travel allowance of 30,000 Cedis (US\$6.60), 5,000 Cedis (US\$1.10) and 25,000 Cedis (US\$5.50) respectively. ADRA, PPAG, MFCS, CARE and PLAN allow their agents to keep 40 percent of the money earned from contraceptive sales. PLAN also provides a 20 percent commission on the sale of drugs, and CARE reimburses all transport costs. Most programs provide other incentives such as bicycles (GRMA, MFCS, MAYDAY, IAE, Amasachina, and PPAG), boots (MAYDAY), raincoats (MAYDAY, CARE), T-shirts (CARE), an initial supply of first aid drug kits (YWCA, PLAN), and food during festive occasions (CCG).

To motivate their agents further GRMA, YWCA and GUNSA plan to institute income-generating activities through either providing seed money for investments or linking agents to organisations that provide agro-based micro-credit facilities.

\section{Program Performance}

Severe problems with the record keeping for all CBD programs prevent a complete comparison of their performance. The only comparable data available, on the average number of contacts with new family planning clients, suggests that two of the programs are significantly outperforming the others (Figure 1). It should be noted, however, that MAYDAY's program suffered a major loss of funding in 1999; during the previous year its agents were seeing approximately 30 new clients per year.

Data on the average number of Couple Years of Protection provided per agent are available for only two programs: 47 for PPAG and 2 for GRMA. A lack of data from GRMA on the number of re-supply clients served precludes a full understanding of the apparent differences in performance between these two programs.

5 1US\$ was equivalent to 4,500 Cedis at the time of the study 
Figure 1: Average Number Of New FP Clients Per CBD Agent In 1999

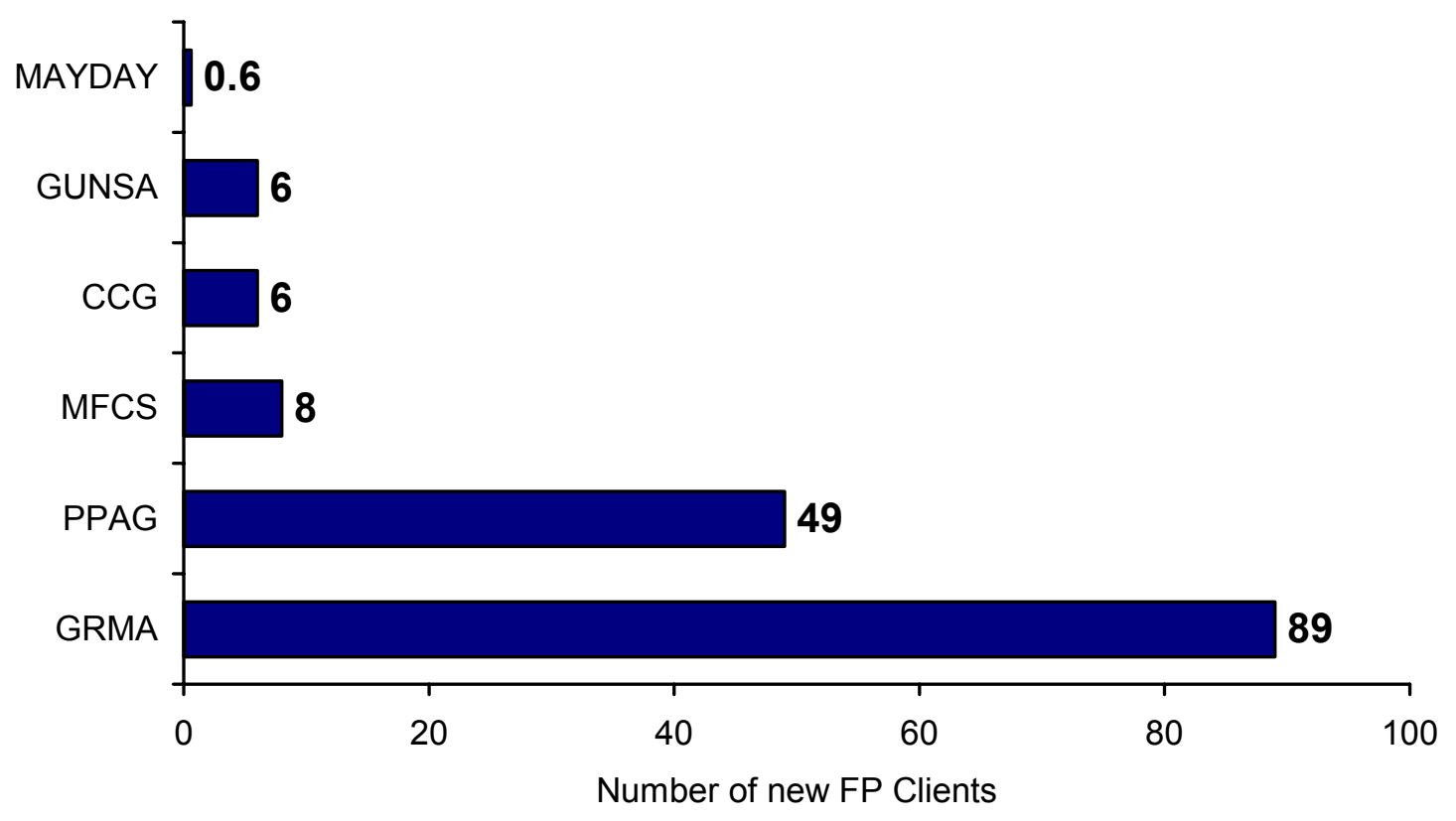




\section{PPAG's CBD PROGRAM}

For 25 years, PPAG has implemented a CBD program that focuses primarily on family planning information and services. It remains the largest in Ghana, with over 850 volunteer agents active in 57 districts of eight regions. Following the 1994 International Conference on Population and Development, PPAG has been seeking a paradigm shift into providing broader sexual and reproductive health services rather than strictly family planning. Following a pilot study in 1996, it integrated the broader sexual health approach into its CBD programs. Today, all agents have received some limited training in STIs and HIV/AIDS education. The organization also works with peer educators.

PPAG is currently implementing three CBD models: the traditional model, the sexual health model, and the youth peer educator model (see box). Data were collected at the district level to represent PPAG's district-level administration, and districts were selected so as to represent both the three models and all eight regions. One district in Ashanti Region was selected to represent the sexual health model; four districts in Volta and Eastern Regions were selected to represent the peer educators' model; and two districts were randomly sampled in each of the remaining five regions to represent the traditional model. Two of these districts (Accra and Kumasi) were purposively selected to represent urban locations.

To assess program performance, $301 \mathrm{CBD}$ agents representing all three models and districts were randomly selected; this sample included 99 female and 202 male agents. All agents were interviewed using in-depth questionnaires, an inventory was taken of their equipment and supplies, and their records abstracted.

Either full-time or part-time supervisors supervise CBD agents, and all 27 supervisors in the 16 selected districts were included for interview. To assess their technical skills and the quality of service provided, a random sample of 51 agents was observed providing services to six family planning clients each.

\section{PPAG's CBD Models}

Traditional model:

- Promote family planning through group and individual meetings

- Provide pills, condoms, and spermicides or refer for clinical methods

- Make follow-up and home visits

- Educate and counsel on STIS

- Treat minor ailments

Sexual health model:

- Same as traditional model except agents trained to start counselling with broad consideration of sexual health rather than focus on family planning

Youth peer educator model:

- Promote family planning through group and individual meetings

- Provide condoms and spermicides or refer for pills and clinical methods

- Make follow-up and home visits

- Educate and counsel on STIS

- Iink with wouth sontros

The agents interviewed ranged between 13 and 71 years, with an average age of 35 years for both women and men. Agents operating as peer educators had a mean age of less than 22. The agents in urban areas are much more likely to be male than female. Agents were both married and unmarried; the highest proportion interviewed were in monogamous marriages and the second highest were single. Most agents have completed junior or secondary school education; very few 
have primary or no formal schooling. The agents interviewed were primarily Protestant Christian, although there were also a number of Catholics and Muslims. Forty percent of agents were peasant farmers, while one quarter were small-scale traders or were running their own businesses. Overall, more than 70 percent of the agents earn some sort of income from other activities.

To get an understanding of the communities' perspective, 15 focus group discussions (FGDs) were held with representatives of different groups from within communities served by each of the CBD models, including youth and adults, clients and non-clients, as well as inactive CBD agents.

For each site selected, all clinics in the CBD catchment area to which CBD agents refer their clients were included. One staff member providing MCH/FP and STD services on the day of the visit was interviewed at each clinic to learn about the clinics' preparedness to serve CBD referral clients, as well as the relationship between CBD agents and the clinics. In all, 20 clinic staff in 20 clinics were interviewed.

\section{Agent Performance}

PPAG agents are required to perform slightly different sets of activities in each of the three CBD models that the organization implements. Family planning remains at the core of their responsibilities and is the activity for which most information is available.

Because of the weaknesses in record keeping and reporting, the outputs produced are inevitably under-reported, and so the figures given below are the minimum performance levels. Because of difficulties in distinguishing CBD agent clients from clinic clients in the youth model, the figures in Table 3 are for those agents in the traditional and sexual health models only. In 1998 there were 924 active agents, and in 1999 there were 853 active agents.

Table 3: Average Number Of Family Planning Outputs Per CBD Agent Per Year

\begin{tabular}{||c|c|c|c|c|c|c|c|c|c||}
\hline \multirow{2}{*}{ Year } & \multicolumn{3}{|c|}{ Family Planning Client Contacts } & \multirow{2}{*}{\begin{tabular}{c} 
Follow-Up \\
IHome \\
\cline { 8 - 10 }
\end{tabular}} & New & Re-supply & Referral & Total & \multicolumn{4}{|c||}{ Visits } & Contraceptives Distributed \\
\hline 1998 & 52 & 120 & 8 & 180 & 92 & 937 & 792 & 262 & 28 \\
\hline 1999 & 49 & 86 & 6 & 141 & 413 & 1,654 & 26 & 545 & 47 \\
\hline
\end{tabular}

The average number of contacts per agent involving family planning clients has dropped, primarily because agents are seeing fewer re-supply clients. However, the CYP provided per agent has increased significantly. This is primarily because agents are almost doubling the number of pill cycles and condoms sold, despite a huge decrease in the number of spermicides sold. 
Agents are expected to make follow-up home visits, and the number of visits appears to have increased dramatically. In addition, agents held group discussions on average 29 times a year or over twice a month in 1999. Within the integrated approach adopted by PPAG, agents are also trained and encouraged to counsel and educate community members on STDs and HIV/AIDS and to treat minor ailments. During 1999, each agent met approximately 31 persons concerning STDs, up from 20 in 1998. They also treated 47 for minor ailments, up from 31 in 1998. A brief summary of the average CBD agent's workload is described in the box, using statistics reported in PPAG's 1999 Annual Report.

In terms of family planning client contacts made, PPAG's program compares favourably with other NGO CBD programs in sub-Saharan Africa that use voluntary agents. This could be attributed to the fact that it is an NGO program that allows its agents to have a commission on commodity sales; in many countries, it is the public sector programs that rely on volunteers. For example, the public sector voluntary CBD programs in Tanzania and Kenya have an average of $90-105$ client contacts per agent per year.

\section{Agent Training}

All agents and supervisors interviewed have received basic training, and 30 percent have received some refresher training. Agents recruited in the late 1990s were more likely to have received refresher training than those who have been with the program longer.

During each month of 1999, the
average CBD agent:
Contacted 12 FP clients
Made 34 follow-up home
visits
Distributed 45 pill cycles,
138 condoms and 2
spermicides
Held 2 group discussions
Met 2 persons for STI
counseling
Treated 3 persons for minor
ailments

\section{Contraceptive Supplies}

Almost all agents receive their supplies from their supervisors or collect them from the PPAG offices. A small proportion (4\%) reported getting supplies from $\mathrm{MOH}$ clinics and drug stores. However, 42 percent of the agents reported experiencing occasional stock outs and had to sometimes refer the clients to drugstores.

Stock outs on the day of interview were quite common, with 27 percent of agents having no pills, 19 percent having no condoms and 37 percent having no foam tablets. There were significant differences between regions, however, with agents in the Greater Accra Region having the highest levels of stock outs. While approximately 80 percent of agents had a bag for carrying their supplies, only about one third had a storage container. 


\section{IEC Materials}

The IEC materials held by agents vary considerably by both type of material and by CBD model in which they work (see Table 4). There is clearly a need for improvement if CBD agents are to be adequately equipped to inform and educate their clients as well as the community at large.

Table 4: Proportion of Agents Who Had IEC Materials By CBD Model

\begin{tabular}{||l|c|c|c|c||}
\hline IEC Material & Traditional $(\mathbf{n}=\mathbf{1 8 8})$ & Youth $(\mathbf{n}=\mathbf{8 5})$ & Sexual Health $(\mathbf{n}=\mathbf{2 8})$ & Total $(\mathbf{n}=\mathbf{3 0 1})$ \\
\hline Flip Chart & 87 & 41 & 100 & 76 \\
\hline HIV Booklet & 35 & 31 & 33 & 34 \\
\hline FP Pamphlets & 37 & 25 & 19 & 81 \\
\hline Penis Model & 90 & 56 & 62 & 16 \\
\hline FP Posters & 27 & 1 & 4 & 12 \\
\hline STD Posters & 20 & 0 & 0 & 6 \\
\hline $\begin{array}{l}\text { Other IEC } \\
\text { Materials }\end{array}$ & 0 & 21 & & \\
\hline
\end{tabular}

\section{Record Keeping And Reporting}

One quarter of the agents did not have a record-keeping book, almost one half did not have a monthly activity report book, and 60 percent did not have a client register (Table 5). With such high proportions of agents being without the basic materials needed to keep records and make reports, it is not surprising that the program statistics available at the district and national levels are incomplete.

Given that record keeping and reporting are clearly a major weaknesses of the program, it was somewhat surprising that only 17 percent of agents and 40 percent of supervisors reported having any problems with this aspect of their work. That there can be such a problem and the staff do not recognize it emphasizes the seriousness of the issue.

In addition to not having the materials to actually prepare and submit reports, during focus group discussion, the inactive CBD agents said that their supervisors did not always request for them. Others reported that they failed to submit reports because the incentives to do so were either nonexistent or not strong enough to motivate them - in other words, they felt that this part of the work required additional incentives, preferably financial. 
Table 5: Proportion of Agents Who Had MIS Materials By CBD Model

\begin{tabular}{||l|c|c|c|c||}
\hline Material (n=298) & $\begin{array}{c}\text { Traditional } \\
(\mathbf{n = 1 8 7})\end{array}$ & $\begin{array}{c}\text { Youth } \\
(\mathbf{n = 8 3})\end{array}$ & $\begin{array}{c}\text { Sexual Health } \\
(\mathbf{n = 2 8})\end{array}$ & $\begin{array}{c}\text { Total } \\
(\mathbf{n = 2 9 8})\end{array}$ \\
\hline Record Keeping Book & 95 & 30 & 96 & 77 \\
\hline Diary & 1 & 0 & 0 & 0.3 \\
\hline Client Register & 44 & 18 & 62 & 40 \\
\hline Client Referral Card & 83 & 56 & 69 & 73 \\
\hline Monthly Activity Report & 59 & 45 & 69 & 57 \\
\hline CBD Monthly Report Form & 35 & 43 & 42 & 39 \\
\hline
\end{tabular}

\section{Supervision}

Two thirds of agents interviewed reported that they had received at least one visit from a supervisor during the previous month (See Figure 2). However, agents with full-time supervisors had more supervisory visits compared to those with part-time supervisors, and urban-based and female agents tend to receive more visits than their rural and male counterparts respectively.

Approximately 60 percent of agents felt that the frequency of supervision was about right. When asked whether the supervisors gave them supportive feedback during the visits, over 90 percent indicated that they did, and most of these said it happened at every visit. This feedback most often related to family planning issues. Agents reported that supervisors most frequently observed them at work, reviewed their records, gave them update training, and re-supplied commodities.

Figure 2: Number Of Supervisory Visits Received Per Agent During The Previous Month

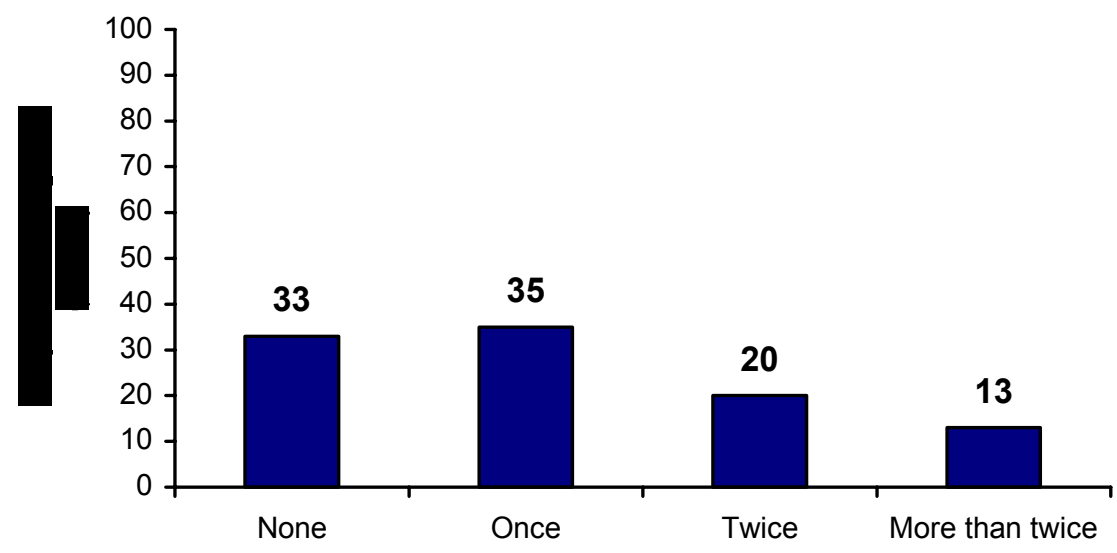




\section{Agent Motivation}

The majority of agents interviewed consider that they receive both monetary and non-monetary incentives. Almost all (94\%) of the agents reported that they receive monetary incentives in the form of 40 percent commission for sale of contraceptives. An analysis of the amount an agent would earn on average from sales indicates that the amount is, indeed, minimal: approximately 2,000 Cedis (US\$0.4) per month or 25,000 Cedis (US\$ 5.5) per year.

Community contributions and other cash payments play little part in the PPAG CBD incentive scheme. Community members were of the view that the PPAG had been providing monetary remuneration to the agents and as such it was not necessary for the community to do so. They were faced with financial problems themselves and could not support the agents financially.

Over 40 percent of the agents mentioned lack of incentives and lack of pay or allowances as some of the things they dislike most about CBD work. The inactive agents interviewed also cited the lack of monetary motivation as a major reason for their inactivity. "I am fed-up with the job, no incentive! No pay! For a long time the condoms and contraceptives do not go fast and commission is very meagre. PPAG never fulfilled most promises. So I do it half-heartedly these days" (Inactive male agent, Ashanti Region.)

However, agents did appreciate some of the non-monetary incentives they received from PPAG 70 percent mentioned the equipment and working tools provided, 45 percent mentioned the training and refresher courses, and 39 percent attending meetings. In addition, the majority (77 percent) of agents reported that they liked the opportunity to be able to help others, more than half (57 percent) mentioned the knowledge gained from training, and one third appreciated the prestige associated with CBD work. 'My people call me 'Doctor' because of this work. I know a lot of things now. Above all, people like me because I help them to space their birth' (Active male agent, Western Region).

\section{Quality Of Care Provided By PPAG Agents}

Through observations of agent-client interactions, the majority (89\%) was judged to have good interpersonal skills. They were able to create good rapport with the client through greeting and inquiring about general well being at the beginning of the interaction.

All agents interviewed have received basic training in family planning, and almost all (92\%) have received training on providing reproductive health information and services to youth. A similar proportion reported receiving training on signs and symptoms of STIs, although it appears that the training emphasized gonorrhea, syphilis and HIV/AIDS, and only half the agents felt the STI training was adequate.

When asked a series of questions about providing contraceptive methods, more than half the agents said they would instruct the client on how to use the pill and would use the checklist to check on contraindications. About half said they would inquire if the client has missed her period to check on pregnancy status. However, less than a third of the agents mentioned seeking information about their client's reproductive goals and breastfeeding status, discuss about 
condom use for STI prevention, inform the woman about side effects and how to manage them, or give the client a date for her next visit.

Knowledge on side effects of the pill was low. Very few agents or supervisors could correctly mention symptoms of severe side effects for which a woman should seek assistance. The majority of agents and supervisors knew what information to provide to a pill client who has forgotten to take the pill for one day but they were less knowledgeable when it is two days.

A composite score for knowledge on family planning indicated a significant difference between agents. The Youth Peer Educators, on average, scored four out of a possible 27 points, whereas agents in the traditional and sexual health models scored between nine and 10 .

When asked to name specific STIs, almost all agents mentioned gonorrhea, HIV/AIDS, and syphilis, but few other infections were mentioned apart from candidiasis (19\%). As would be expected, supervisors were better informed than the agents, and there was a significant difference in knowledge about STIs between agents for the CBD models. The Youth Peer Educators had the highest score and agents in the traditional model scored lowest. A similar trend was observed regarding the proportion of agents who know the various symptoms of STIs although the difference in models in this case was not significant.

Of the 306 interactions observed, 139 were for pill clients, 95 were for condom clients, 20 for foaming tablet clients, and 52 were of referrals for long-term methods. The checklist was used in only 22 percent of the interactions with 95 new pill clients. Of these, it was used correctly for 87 percent of the interactions. For all pill clients, the agents used the checklist in only 19 percent of the interactions. In over two-thirds of the cases, the agents asked questions to assess if the resupply client was experiencing any problems with the pill.

These observations revealed that on average, most agents provide the required information to their clients:

- Over 60 percent of pill clients were provided information regarding how to use the pill, what to do if they miss the pill for one day, where to get a supply of pills, and the cost of the pills.

- Over 80 percent of condom clients received information about the dual purpose of condoms, how to dispose of used condoms and the cost of condoms. Over two thirds of new condom clients had the agent demonstrate how to use the condom.

- Over four-fifths of foaming tablet clients were told how to use the method, and over two-thirds were informed about sources and the cost of foaming tablets.

- Almost all the clients who chose a long-term method received information regarding where to get the method and 60 percent received information regarding the advantages of the long-term methods.

However, some important information was not provided. Less than half of the new pill clients received information regarding side effects and how to manage them. About half of the new condom clients did not receive information on other sources of condom. Over two-thirds of the 
foaming tablet clients were not told that they should wait for at least six hours after having sex before washing, and over three-quarters were not given the recommendation to also use condoms. Less than half of the long-term method clients received information regarding the cost of the method they had chosen.

\section{Service Integration}

With the global re-orientation of family planning programs towards more comprehensive service provision, all of PPAG's CBD agents are expected to offer STI information and referral services and for the Traditional and Sexual Health models, some $\mathrm{MCH}$ information and referral services. During the agent-client interactions observed, the following actions concerning an integrated approach were seen:

- All clients requiring services that the agents could not themselves provide were referred to the appropriate health facility.

- Half of the clients observed had children below two years of age, but agents discussed immunization and child monitoring with only 22 percent of these clients.

- In the majority of cases, agents discussed STI/HIV issues with their clients. Most agents gave information about how to prevent infection (92\%), symptoms of infection (74\%), where to get care if one is infected (74\%) and STI risk factors $(63 \%)$.

- However, in only half of the interactions did agents enquire about the client's personal behavior, and in only nine percent of them did they ask the client about the presence of STI symptoms.

The most common reason why clients are referred is for services/methods not supplied by the agents, or for a medical check-up for general health problems. Referral clinic staff interviewed confirmed that, in addition to family planning services, agents refer their clients for treatment of minor ailments, malaria, diarrhea, infertility, post-abortion care, menopausal problems, and boygirl relationship counseling.

Agents reported that they predominantly refer their clients to PPAG and MOH clinics. However, one-third of the agents had never been introduced to the referral clinic staff by their supervisor. Out of these, 40 percent had not made any effort to introduce themselves either.

For those who have met the clinic staff, virtually all described their relationship as very cordial, friendly or nice. Over half of the agents felt that their working relationship would be improved if they were introduced to the clinics.

\section{Services For Youth}

Two of PPAG's CBD models are explicitly oriented towards serving youth, that is, young people between 10 and 24 years. Because of this, the survey collected information from agents and 
supervisors about their attitudes towards serving youth and their knowledge of some of the special circumstances facing youth.

Both agents and supervisors appear to have a biased attitude towards providing services to youth who have not given birth. Whereas 85 percent of agents and 23 out of 27 supervisors will provide services to a girl with a child at any age, for a girl or a boy without a child the proportions are much lower at about 15 percent only. There was a significant difference between regions, with agents from the Volta, Central, Greater Accra, and Western Regions more willing to offer services to youth with or without children at any age than their counterparts from the other regions. Female agents had a more favourable attitude towards provision of services to a boy or girl without a child at any age.

Agents were also asked who they thought had the primary responsibility for providing reproductive health information to the youth. Thirty-three percent thought parents should do it, 30 percent thought CBD agents themselves should and 20 percent said other health care providers should.

Agents and supervisors appear to be fairly knowledgeable about the physical and emotional changes experienced by adolescents at puberty, and of the health risks associated with adolescent pregnancy. With respect to boys, agents were twice as likely to mention their physical development (e.g. voice deepening, pubic hair, muscle development) than development of their sex organs. For adolescent girls, breast enlargement, pubic hair and menstruation were the most commonly mentioned. Although, as would be expected, agents from the Youth Peer Educator and Sexual Health models were more knowledgeable, the difference between them and agents in the traditional model was not great.

Knowledge of the health risks of adolescent pregnancies was not strong across all three models: only delivery complications and maternal death were mentioned by over half of the agents. Similarly, agents could not identify many of the traits of emotional changes during adolescence, with only "hard to talk to" and "insecure about appearance" being mentioned by more than half of the agents. 


\section{UTILIZATION OF THE STUDY FINDINGS}

PPAG staff were exposed to the limitations in their program implementation during the data collection exercise, data interpretation workshop and during the national and zonal workshops held to disseminate the findings of this study and solicit recommendations from participants. The PPAG CBD program staff have been quick in utilizing the findings of the study to improve the implementation of their program. PPAG has so far taken the following measures:

a) General improvements in the program implementation. PPAG has:

- Set up a committee to review the CBD manual and protocols and make necessary recommendations for improvement.

- Taken a decision to have every agent undertake a community diagnosis exercise to identify, map and record the number of households, population of the various age groups, users and non-users in his/her catchment area.

- Planned to implement a study to assess the cost-effectiveness of the two supervision strategies currently in place, that is, use of part-time and full-time supervisors.

b) Improvements in MIS and record keeping. PPAG has:

- Developed new record keeping formats for CBD agents and their supervisors. The new CBD record keeping formats are now in duplicate for the CBD to retain the copy and forward the original to the supervisor. The supervisors' formats are in triplicate for them to retain a copy, send the other copy to the zonal office and the original to the headquarters. This will ensure the availability of individual CBD monthly output report at the CBD, and supervisor levels and the individual supervisor's monthly reports at all the other supervisory levels.

- Purchased diaries for all the CBD agents and their supervisors.

c) Improvement in the CBD clinic referral system. PPAG has:

- Put in place a system to have referral boxes for each CBD referral point to enable supervisors to check and record CBD effective referrals on a monthly basis.

- Taken the decision to provide orientation to staff in all the referral points in CBD catchment areas.

d) Improvement in provision of IEC materials:

- The committee reviewing the CBS manual is also mandated to look into the issue of flip charts and ensure that all CBD agents are provided with the necessary flip charts to enable them counsel clients effectively. 


\section{CONCLUSION AND RECOMMENDATIONS}

\section{All NGO CBD Programs}

CBD programs implemented by NGOs are emerging rapidly all over Ghana. With slight variations, they are following a similar model that seeks to provide a range of reproductive health services beyond family planning, uses a fairly standardized training curriculum, relies on volunteer agents, and is implemented independently of other CBD programs. Because of poor record keeping and reporting, however, it is virtually impossible to assess and compare the performance of these programs, although it appears that even the best-reported programs are performing at or below what is being achieved by similar programs in other African countries. The study results also suggest the following.

- There is an urgent need for standard norms and guidelines for CBD programs in Ghana that provide reproductive health information and services. Much evidence is available on better practices for CBD programs from Ghana and other African countries. This experience should be tapped to guide their development. Particular attention should be paid to the issues of agent motivation and supervision, as well as financial sustainability.

- NGO programs may benefit from better co-ordination of their activities amongst themselves as well as with the Ministry and commercial marketing programs. This would help to ensure equitable coverage across the country as well as to facilitate the development and adaptation of appropriate and effective operating procedures.

- Highest priority should be given to strengthening CBD programs' record keeping and reporting systems so that programs and their donors can monitor performance and strategically plan future directions. This should include the development and implementation of a standardized reporting system that includes mandatory reporting to the NPC and the MOH.

\section{PPAG's CBD Program}

PPAG's CBD program is the oldest, largest and most well developed in the country. In recent years PPAG has recognized the need to re-orientate its approach to implementing communitybased services so that it can reach a wider audience and offer a more comprehensive and integrated range of information and services. The inclusion of STI and HIV/AIDS services in its traditional programs, and the piloting of their Sexual Health and Peer Educator models are good examples of this response to changing needs.

The PPAG program has been evolving over a long time, and so the experiences described by this study should be valuable to many of the other NGOs that are just starting CBD programs. Because of poor record keeping and reporting, it is difficult to assess the program's true performance, but the data that are available suggest that, for a program based primarily on volunteers, it is performing quite well compared to similar programs in other countries of the region. These findings suggest that: 
- As with other NGO CBD programs in Ghana, PPAG needs to strengthen its MIS at all levels so that it is better able to monitor, evaluate, and plan its activities.

- Lack of monetary incentives is affecting agent performance. It is clear that commission on contraceptive sales is insufficient as a material incentive. While financial sustainability is an important consideration when deciding the proportion of its running costs that a CBD program can allocate towards agents' motivation, there is need also to consider the level of agent productivity and dropouts that may result from an insufficient allocation. Therefore, PPAG should seriously consider alternative ways of motivating agents and part-time supervisors, through strategies such as community financing, seed money for income generating activities, small monthly allowances, and linking-up agents with micro-credit agencies.

- Quality of services provided by PPAG agents is acceptable, but they will require occasional updating to maintain and improve further their technical capacity. To enable agents to use the pill checklist effectively, it should be translated into vernacular languages.

- The integration of STI education into interactions with family planning clients appears to be successful and needs to be sustained, although it needs to be expanded beyond the limited range of infections currently being covered. One weakness, however, is that agents tend not to ask about the client's personal risk factors and symptoms, that is, to do some preliminary screening for possible infections. This would further strengthen this aspect of integration.

- PPAG should improve its commodity logistics management system to ensure that at least the minimum stock of commodities is available to all agents at any given time.

- PPAG should ensure that both agents and supervisors meet regularly with the referral clinic staff to ensure that clients benefit from the referral activity.

It was not possible to gain a full understanding of the coverage provided by CBD programs, their effectiveness or their cost-effectiveness because of limitations in the availability of data. The potential would appear to exist, however, for a national scaling up of the proportion of the population served by NGO programs because every district in the country has at least one program represented, and because most programs follow a similar model of service delivery. The PPAG program is fairly typical of NGO programs in Ghana, and so this detailed assessment gives useful insights into how most NGO CBD programs in Ghana could be strengthened. Whether significant resources should be allocated to expanding and improving these programs, however, is a decision that would require an analysis of the costs required to implement such programs so that the cost-effectiveness of this model of service delivery can be compared with others. 


\section{REFERENCES}

Ghana DHS, 1993, 1998. Ghana Demographic and Health Survey Ghana. Statistical Services and Demographic and Health Surveys Macro International Inc.

INTRA/PRIME. 1996. Technical Report Assessment of Community-Based Distribution in the Republic of Ghana International Training in Health.

JOICFP/PPAG 1998. Community Based Distribution: Ghana's Experience. PPAG, Ghana.

Phillips J. and W. Green. 1993. Community-Based Distribution of Family Planning in Africa:

Lessons From Operations Research. Population Council, New York, USA.

Africa Operations Research and Technical Assistance II Project. 1999. Community Based Distribution Program Brief. Population Council, Nairobi, Kenya. 


\section{APPENDIX}

\section{CBD Programs Coverage by Districts}

\begin{tabular}{|c|c|c|c|c|}
\hline \multirow[t]{2}{*}{ Region/District } & \multicolumn{3}{|c|}{ PPAG Programs } & \multirow[t]{2}{*}{ Other Organisations } \\
\hline & $\begin{array}{l}\text { USAID } \\
\text { CBD }\end{array}$ & $\begin{array}{l}\text { (IP) } \\
\text { CBD }\end{array}$ & $\begin{array}{c}\text { Peer } \\
\text { Educators }\end{array}$ & \\
\hline \multicolumn{5}{|l|}{ Greater Accra Region } \\
\hline 1. $\mathrm{AMA}$ & $\checkmark$ & & $\checkmark$ & $\begin{array}{l}\text { GRMA, YWCA, CCG, GUNSA, MFCS, } \\
\text { 31st DWM }\end{array}$ \\
\hline 2. Dangbe East & $\checkmark$ & & & GRMA, SCF, 31st DWM \\
\hline 3. Dangbe West & $\checkmark$ & & & GRMA, YWCA, 31st DWM, CENCOSAD \\
\hline 4. $\mathrm{Ga}$ & $\checkmark$ & & $\checkmark$ & $\begin{array}{l}\text { GRMA, GUNSA, MAYDAY, 31st DWM, } \\
\text { PLAN }\end{array}$ \\
\hline 5. Tema & $\checkmark$ & & & GRMA, GUNSA, 31st DWM, CCG \\
\hline \multicolumn{5}{|l|}{ Central Region } \\
\hline $\begin{array}{l}\text { 6. Abura-Asebu- } \\
\text { kwamankese }\end{array}$ & & & & GRMA \\
\hline 7. Agona & $\checkmark$ & & & GRMA \\
\hline $\begin{array}{l}\text { 8. Asikuma Odoben } \\
\text { Brakwa }\end{array}$ & & & & GRMA \\
\hline 9. Assin & $\checkmark$ & & & GRMA \\
\hline 10. Awutu-Efutu Senya & & $\checkmark$ & & GRMA, PLAN \\
\hline 11. Capecoast & & & $\checkmark$ & GRMA \\
\hline $\begin{array}{l}\text { 12. Ajumaku-Enyam- } \\
\text { Esiam }\end{array}$ & & & & GRMA \\
\hline 13. Gomoa & $\checkmark$ & $\checkmark$ & & GRMA \\
\hline
\end{tabular}




\begin{tabular}{|c|c|c|c|}
\hline $\begin{array}{l}\text { 14. Komenda-Edina- } \\
\text { Eguafo-Abirem }\end{array}$ & & & GRMA, YWCA \\
\hline 15. Lower Denkyira & $\checkmark$ & & GRMA \\
\hline 16. Mfantseman & & & GRMA, PLAN \\
\hline 17. Upper Denkyira & & & GRMA \\
\hline \multicolumn{4}{|l|}{ Western Region } \\
\hline 18. Ahanta West & $\checkmark$ & & GRMA \\
\hline 19. Aowin-Suaman & & & GRMA, SCF \\
\hline $\begin{array}{l}\text { 20. Bibiani Anhwiaso- } \\
\text { Bekwai }\end{array}$ & & & GRMA \\
\hline 21. Jomoro & & & GRMA \\
\hline 22. Juabeso-Bia & & & GRMA \\
\hline $\begin{array}{l}\text { 23. Mpohor Wassa } \\
\text { East }\end{array}$ & $\checkmark$ & & GRMA \\
\hline 24. Nzima East & $\checkmark$ & & GRMA \\
\hline 25. Sefwi Wiawso & & & GRMA \\
\hline $\begin{array}{l}\text { 26. Shama Ahanta } \\
\text { East }\end{array}$ & $\checkmark$ & $\checkmark$ & GRMA \\
\hline 27. Wassa West & $\checkmark$ & & GRMA, CARE \\
\hline 28. Wassa-Amenfi & & & GRMA, SCF \\
\hline \multicolumn{4}{|l|}{ Volta Region } \\
\hline 29. Akatsi & & & GRMA, IAE, 31st DWM \\
\hline 30. $\mathrm{Ho}$ & & & GRMA, IAE, 31st DWM, CC \\
\hline 31. Hohoe & & & GRMA, IAE, 31st DWM, CC \\
\hline 32. Jasikan & & & GRMA, IAE, 31st DWM \\
\hline 33. Kadjebi & & & GRMA, IAE, 31st DWM \\
\hline 34. Keta & & & GRMA, IAE, 31st DWM, YWCA \\
\hline 35. Ketu & & & GRMA, IAE, 31st DWM, YMCA \\
\hline
\end{tabular}




\begin{tabular}{|c|c|c|c|c|}
\hline 36. Kpando & & & & GRMA, IAE, 31st DWM, CCG \\
\hline 37. Krachi & & & & GRMA, IAE, 31st DWM \\
\hline 38. Nkwanta & & & & GRMA, IAE, 31st DWM \\
\hline 39. North Tongu & & & $\checkmark$ & GRMA, IAE, 31st DWM \\
\hline 40. South Tongu & & & $\checkmark$ & GRMA, IAE, 31st DWM \\
\hline \multicolumn{5}{|l|}{ Eastern Region } \\
\hline 41. Afram Plains & & & & GRMA, 31st DWM \\
\hline 42. Akim East & $\checkmark$ & & & GRMA, 31st DWM \\
\hline 43. Akim West & $\checkmark$ & & & GRMA, 31st DWM \\
\hline 44. Akwapim North & & & $\checkmark$ & GRMA, 31st DWM, YWCA \\
\hline 45. Akwapim South & & & & GRMA, 31st DWM, MAYDAY \\
\hline 46. Asuogyaman & $\checkmark$ & & & GRMA, 31st DWM \\
\hline 47. Birim North & & $\checkmark$ & $\checkmark$ & GRMA, 31st DWM \\
\hline 48. Birim South & & & & GRMA, 31st DWM \\
\hline 49. Fanteakwa & $\checkmark$ & & & GRMA, 31st DWM \\
\hline 50. Kwabibirem & $\checkmark$ & & & GRMA, 31st DWM \\
\hline 51. Kwahu South & $\checkmark$ & & & GRMA, 31st DWM, ADRA, SCF \\
\hline 52. Manya Krobo & $\checkmark$ & & & GRMA, 31st DWM \\
\hline 53. New Juabem & $\checkmark$ & & & GRMA, 31st DWM, YWCA \\
\hline $\begin{array}{l}\text { 54. Suhum Kraboa } \\
\text { Coaltar }\end{array}$ & $\checkmark$ & & & GRMA, 31st DWM \\
\hline 55. Yilo Krobo & $\checkmark$ & & & GRMA, 31st DWM, PLAN, \\
\hline \multicolumn{5}{|l|}{ Ashanti Region } \\
\hline 56. Adansi East & $\checkmark$ & & & GRMA, 31st DWM, YDF \\
\hline 57. Adansi West & $\checkmark$ & & & GRMA, 31st DWM, YDF \\
\hline
\end{tabular}




\begin{tabular}{|c|c|c|c|}
\hline 58. Afigya Sekyere & $\checkmark$ & & GRMA, 31st DWM \\
\hline 59. Ahafo Ano North & & & GRMA, 31st DWM \\
\hline 60. Ahafo Ano South & $\checkmark$ & & GRMA, 31st DWM \\
\hline 61. Amansie East & $\checkmark$ & & GRMA, 31st DWM, YDF \\
\hline 62. Amansie West & & & GRMA, 31st DWM \\
\hline 63. Asante Akim North & $\checkmark$ & & GRMA, 31st DWM \\
\hline 64. Asante Akim South & $\checkmark$ & & GRMA, 31st DWM \\
\hline 65. Atwima & $\checkmark$ & & GRMA, 31st DWM \\
\hline $\begin{array}{l}\text { 66. Bosomtwi-Atwina- } \\
\text { Kwanwoma }\end{array}$ & $\checkmark$ & & GRMA, 31st DWM \\
\hline 67. Ejisu Juaben & $\checkmark$ & & GRMA, 31st DWM \\
\hline $\begin{array}{l}\text { 68. Ejura } \\
\text { Sekyedumase }\end{array}$ & & & GRMA, 31st DWM, SCF \\
\hline 69. Kumasi & $\checkmark$ & $\checkmark$ & $\begin{array}{l}\text { GRMA, 31st DWM, CC, SCF, ADRA, } \\
\text { MFCS, YDF }\end{array}$ \\
\hline 70. Kwabre & $\checkmark$ & & GRMA, 31st DWM \\
\hline 71. Offinso & $\checkmark$ & & GRMA, 31st DWM, YWCA, SCF \\
\hline 72. Sekyere East & $\checkmark$ & & GRMA, 31st DWM \\
\hline 73. Sekyere West & $\checkmark$ & & GRMA, 31st DWM \\
\hline \multicolumn{4}{|l|}{ Brong Ahafo } \\
\hline 74. Asunafo & & & GRMA, 31st DWM \\
\hline 75. Asutifi & & & GRMA, 31st DWM \\
\hline 76. Atebubu & & & GRMA, 31st DWM \\
\hline 77. Berekum & & & GRMA, 31st DWM \\
\hline 78. Dormaa & & & GRMA, 31st DWM \\
\hline 79. Jaman & & & GRMA, 31st DWM \\
\hline 80. Kintampo & & & GRMA, 31st DWM \\
\hline
\end{tabular}




\begin{tabular}{|c|c|c|c|}
\hline 81. Nkoranza & $\checkmark$ & & GRMA, 31st DWM \\
\hline 82. Sene & & & GRMA, 31st DWM \\
\hline 83. Sunyani & $\checkmark$ & $\checkmark$ & GRMA, 31st DWM, MFCS \\
\hline 84. Tano & $\checkmark$ & & GRMA, 31st DWM, YWCA \\
\hline 85. Tekyiman & $\checkmark$ & & GRMA, 31st DWM, YMCA \\
\hline 86. Wenchi & $\checkmark$ & & GRMA, 31st DWM \\
\hline \multicolumn{4}{|l|}{ Northern Region } \\
\hline 87. Bole & & & $\begin{array}{l}\text { GRMA, 31st DWM, Amasachina, Action } \\
\text { Aid }\end{array}$ \\
\hline 88. Dagomba East & $\checkmark$ & & $\begin{array}{l}\text { GRMA, 31st DWM, Amasachina, Action } \\
\text { Aid }\end{array}$ \\
\hline 89. Dagomba West & $\checkmark$ & & $\begin{array}{l}\text { GRMA, 31st DWM, Amasachina, Action } \\
\text { Aid }\end{array}$ \\
\hline 90. Gonja East & $\checkmark$ & & GRMA, 31st DWM, Amasachina, SCF \\
\hline 91. Gonja West & & & $\begin{array}{l}\text { GRMA, 31st DWM, Amasachina, Action } \\
\text { Aid }\end{array}$ \\
\hline 92. Gushiegu Karaga & $\checkmark$ & & GRMA, 31st DWM, Amasachina \\
\hline 93. Mamprusi East & & & GRMA, 31st DWM, Amasachina \\
\hline 94. Mamprusi West & $\checkmark$ & & $\begin{array}{l}\text { GRMA, 31st DWM, Amasachina, SCF, } \\
\text { Action Aid }\end{array}$ \\
\hline 95. Nanumba & & & $\begin{array}{l}\text { GRMA, 31st DWM, Amasachina, SCF, } \\
\text { Action Aid }\end{array}$ \\
\hline 96. Saboba Chereponi & & & GRMA, 31st DWM, SCF, Action Aid \\
\hline 97. Savelugu Nantom & $\checkmark$ & & GRMA, 31st DWM, Amasachina \\
\hline 98. Tolon Kumbugu & $\checkmark$ & & GRMA, 31st DWM, Amasachina \\
\hline 99. Zabzugu Tatali & & & GRMA, 31st DWM, Amasachina \\
\hline
\end{tabular}




\begin{tabular}{|c|l|l|l|l|}
\hline Upper West & & & & \\
\hline 100. Jirapa Lambussie & & & & GRMA, IAE \\
\hline 101. Lawra & & & & GRMA, IAE \\
\hline 102. Nadawli & $\checkmark$ & & & GRMA, IAE, Action Aid, SCF \\
\hline 103. Sissala & & & & GRMA, IAE, Action Aid \\
\hline 104. Wa & & & & GRMA, IAE \\
\hline Upper East & & & & GRMA, IAE, SCF \\
\hline 105. Bawku East & & & & GRMA, IAE, Action Aid \\
\hline 106. Bawku West & & & & GRMA, IAE \\
\hline 107. Bolgatanga & & & & GRMA, IAE \\
\hline 108. Bongo & & & & \\
\hline 109. Builsa & & & & \\
\hline 110. Kassena & & & & \\
\hline Notal & & & & \\
\hline
\end{tabular}

